\title{
The Magnitude of Refractive Error
}

\section{Gaurav Dubey ${ }^{1}$, Dr Kamal Pant ${ }^{1 *}$, Vibha Kumar ${ }^{2}$, Jamshed Ali ${ }^{3}$, Ragni Kumari $^{4}$ and Dr Mahesh Chandra ${ }^{5}$}

${ }^{1}$ Department of Optometry, FPS, UPUMS Saifai Etawah

${ }^{2}$ Department of Paramedical Sciences, Jamia Hamdard New Delhi India

${ }^{3}$ Department of Optometry, Allied Health Science IIMT University, Meerut, Uttar

Pradesh India

${ }^{4}$ Department of Optometry, Era University Lucknow

${ }^{5}$ Dr. Sushila Tewari Hospital and Govt. Medical College, Haldwani, Uttarakhand India

*Corresponding Author: Dr. Kamal Pant, Department of Optometry, FPS, UPUMS

Saifai Etawah

Keywords: Refractive Error; Magnitude; Global Prevalence; Blindness

Refractive errors affect a larger proportion of the world's population, regardless of age, ethnicity, or ethnic group. Globally, 2.3 billion individuals are known to have refractive errors, with (1.8) billion having access to appropriate eye exams and inexpensive corrections, and (500 million) have uncorrected errors that cause blindness or impaired vision (mostly in developing nations) [1]. They are a significant cause of poor vision and even blindness, if not corrected. However, they can be easily detected, measured, and corrected with spectacles and other refractive corrections [2]. An uncorrected refractive error has been identified as the leading cause of visual impairment in Asian school-aged populations [3-6] \{Hispanic and European\} $[7,8]$. The prevalence of vision loss due to refractive error was reported to be as high as 0.36 percent in India for all age groups in a population considered together, with blindness characterized as presenting length visual acuity $\{<3 / 60$ in the better eye [9]. Refractive error is the second most common eye problem in Indian school-going children. The most common cause of defective vision in school children is refractive errors. Children younger than 15 years make up about $42 \%$ of the population in India. The fact is that 30 percent of kids lose their eyesight before 20 years of age. Uncorrected refractive error in children and its consequences profoundly impact their overall development, particularly on educational and developing health $[10,11]$. In children, refractive error may affect the child's level of reading and have a negative impact on overall learning. It can even lead to a long-lasting and correctable vision degradation called refractive amblyopia. In adults, having blurry vision, especially while driving or operating machinery, can be uncomfortable, inconvenient, and even unsafe. Kids often do not complain about decreased vision and may not even be conscious of their issues. Changing the classroom position, participating in physical activity closely, and tending to avoid jobs that involve more visual concentration can save them from having poor vision $[12,13]$.
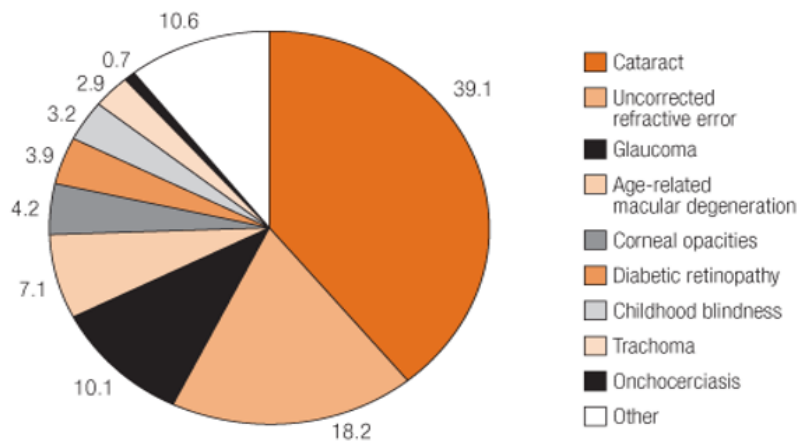

Figure 1: Global cause of blindness (2004) [14]

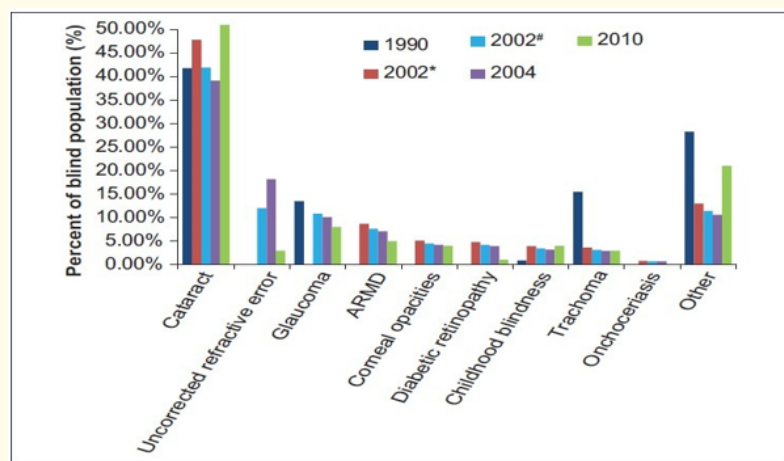

Figure 2: [Global. causes of blindness]: 1990-2010* (*xcluding. refractive error, \# Including. refractive error.) [15] 


\section{Conflict of Interest}

None.

\section{Bibliography}

1. Holden BA., et al. "The Challenge of Providing Spectacles in the Developing World". The Community Eye Health Journal 13. 33 (2000): 910.

2. Resnikoff S. "Global magnitude of visual impairment caused by uncorrected refractive errors in 2004". Bulletin of the World Health Organization 86.1 (2008): 63-70.

3. Dandona R., et al. "Refractive Error in Children in a Rural Population in India". Investigative Ophthalmology and Visual Science 43 (2002) :615-622.

4. Fan DS., et al. "Prevalence, Incidence, and Progression of Myopia of School Children in Hong Kong". Investigative Ophthalmology and Camp Visual Science 45.4 (2004): 1071.

5. Zhao J., et al. "Refractive error study in children: results from Shunyi District, China". American Journal of Ophthalmology 129.4 (2000): 427-435.

6. Lin LL-K., et al. "Nation-wide survey of myopia among schoolchildren in Taiwan. 1986". Acta Ophthalmologica 66.S185 (2009): 29-33.

7. Villarreal MG., et al. "The refractive tendency in teenagers. Prevalence of myopia among young teenagers in Sweden". Acta Ophthalmologica Scandinavica 78.2 (2000): 177-181.

8. Dandona L., et al. "What is the global burden of visual impairment>"? BMC Medicine 4.1 (2006).

9. Key Findings - NPCBVI (2021).

10. Pratt C., et al. "Children Understand That Looking Leads to Knowing (So Long as They Are Looking into a Single Barrel)". Child Development 61.4 (1990): 973.

11. Packwood EA. "The psychosocial effects of amblyopia study". Journal of American Association for Pediatric Ophthalmology and Strabismus 3.1 (1999): 15-17.

12. Niroula DR., et al. "Study on the refractive errors of school going children of Pokhara city in Nepal". Kathmandu University Medical Journal 7.25 (2009): 67-72.

13. Khan NA., et al. "Prevalence of refractive error among school children in North-West Rajasthan". International Journal of Biomedical 7.12 (2016): 565-568.

14. Resnikoff., et al. "Global magnitude of visual impairment caused by uncorrected refractive errors in 2004". Bulletin of the World Health Organization 86. (2008): 63-70.
15. Resnikoff., et al. "Future trends in global blindness". Indian Journal of Ophthalmology 60 (2012): 387-395.

Volume 4 Issue 9 September 2021

(C) All rights are reserved by Gaurav Dubey., et al. 